\title{
Endoscopic Ultrasonography in Tumor of Pancreas in Childhood. Case Report
}

\section{Norberto C Alfonso Contino ${ }^{1}$, Raúl Brizuela Quintanilla ${ }^{2 *}$, Jorge Luis García-Menocal Hernández ${ }^{1}$, Julieth Suarez Oceguera $^{3}$, Yanet Ortega Dugrot $^{3}$ and Claudia Caraballo ${ }^{3}$}

${ }^{1}$ Specialist in Gastroenterology, National Center for Minimal Access Surgery, Ministry of Public Health, Havana, Cuba

${ }^{2}$ Second Degree Specialist in Gastroenterology, Full Professor, National Center for Minimal Access Surgery, Ministry of Public Health, Havana,

Cuba

${ }^{3}$ Licensed in Nursing, Assistant Professor, Aggregate Investigator, National Center for Minimal Access Surgery, Ministry of Public Health, Havana, Cuba

*Corresponding Author: Raúl A. Brizuela Quintanilla, Second Degree Specialist in Gastroenterology, Full Professor, National Center for Minimal Access Surgery, Ministry of Public Health, Havana, Cuba.

Received: July 12, 2019; Published: July 30, 2019

DOI: 10.31080/ASGIS.2019.02.0067

\section{Abstract}

Cancer is a rare disease in children and adolescents, however in recent years, it has been presenting a considerable increase in its frequency.

Methods: We present the case of a 5-year-old boy who presented with abdominal pain, vomiting and fever. A palpable mass was detected in the epigastrium on physical examination and ultrasound diagnosis, confirmed by computerized axial tomography, of the lesion in the uncinate process of the pancreas. Is sent for the realization of an endoscopic ultrasound and FNA, confirming by histological study, possible papillary cystic tumor of the pancreas, corroborated later in the histological study of the surgical piece.

Results: We describe the most relevant aspects of this type of tumors with emphasis on recent advances in endoscopic techniques with ultrasound that have allowed to define diagnostic criteria and introduce new behaviors, with encouraging results in pediatrics Conclusion: The knowledge and management of endoscopic ultrasonography as a new advanced technique allows the accurate and rapid diagnosis of benign and malignant conditions in pediatrics and allows us to adopt appropriate therapeutic behaviors over time.

Keywords: Cancer; Tumors; Pancreas; Endoscopic Ultrasonography

Declaration of informed consent: Informed consent was obtained from the patient's relatives.

Conflict of interest statement: No potential conflicts of interest relevant to this article were reported.

\section{Introduction}

Cancer is a rare disease in children and adolescents, however, in recent years, it has been presenting a considerable increase, until today it is one of the leading causes of infant mortality in the world $[1]$.
Solid pseudopapillary tumors of the pancreas are infrequent and represent 1 to $2 \%$ of pancreatic tumors, although there is an apparent increase in their incidence in recent years, which can be attributed to diagnostic techniques with higher resolution. Before 1997 they were called solid and cystic neoplasm of the pancreas, or papillary and cystic neoplasm of the pancreas. They are neoplastic lesions with a low malignant and metastatic potential [2].

The symptoms are nonspecific and the most frequently reported are: abdominal pain, abdominal mass and feeling of fullness. Less 
commonly, obstruction, bowel, anemia, jaundice, pancreatitis, biliary obstruction, or traumatic rupture with hemoperitoneum have been reported. In children, the most commonly reported clinical presentation is a palpable mass [3].

The treatment of choice is resection by radical pancreatoduodenectomy (Whipple), with free margins [4].

Endoscopic ultrasound is a valuable tool in the evaluation of gastrointestinal lesions. The combination of endoscopic visualization and high frequency ultrasound images of the gastrointestinal tract allows for diagnostic and therapeutic procedures, as well as the evaluation of pancreatobiliary lesions and submucosal lesions. It is very useful and safe, particularly in punctures with fine needle aspiration (FNA), since an index of $1 \%$ to $2 \%$ of complications is associated [5].

\section{Case Report}

Child of 5 years, white, with weight $21.5 \mathrm{~kg}$ and size $113 \mathrm{~cm}$. Personal pathological history of tonsillitis. Healthy lifestyle, without previous surgical interventions. Go to the emergency department with abdominal pain of 11 days of evolution, fever and nausea.

\section{Physical exam}

Abdomen; slight accentuation of pain to deep palpation, as well as a palpable mass in the epigastrium.

\section{Complementary exams}

Laboratory tests showed normal values.

The abdominal ultrasound diagnosis was of an isoechogenic, homogeneous image, $51 \times 26 \mathrm{~mm}$, regular contours, in the uncinated process of the pancreas. No calcifications. No adenomegalias.

The computerized axial tomography showed a tumor image, of $36 \times 36 \mathrm{~mm}$ isodense appearance, without calcifications, of regular contours in the uncinated process of the pancreas.

The patient is referred to the National Center for Minimum Access Surgery for the study and sample of the lesion by endoscopic ultrasound.

Interventional endoscopic ultrasonography; the presence of a tumor image of $25 \times 13 \mathrm{~mm}$, of well-defined contours is corroborated. A sample of the lesion is taken by puncture with fine needle aspiration (PAAF) for histological study.
The Anatomopathological report was a cystic tumor lesion, with the possibility of being a solid papillary cystic tumor of the pancreas and resection is recommended for definitive diagnosis.

\section{Therapeutic intervention}

Radical pancreatoduodenectomy (Whipple) was performed, with pyloric resection. In the surgical exploration, an expansive tumor of $3 \mathrm{x} 4 \mathrm{~cm}$ was found, not infiltrating in the head of the pancreas. Adenopathies were identified without suspicion of infiltration. No hepatic or peritoneal metastases were observed.

In the study of the surgical piece, the histology of the lesion was verified, being a pseudopapillary cystic tumor of the pancreas. Without metastatic ganglia.

\section{Discussion}

According to the bibliography consulted, studies conducted by Laffita Estévez and collaborators [6], and Verdecia Cañizares [7] report that cancer in Cuba is a disease that has been increasing in recent years, with less frequency in the incidence of cancer of pancreas.

In the research conducted by Bender., et al. [4] and Higuita., et al [2], solid pseudopapillary tumors of the pancreas are more common in female patients in the case of schoolchildren, and their most frequent location is in the head of the pancreas, with symptoms similar to those presented in our case, abdominal pain located in the epigastrium is the most common.

In the experience accumulated by the authors, in the realization of therapeutic procedures and diagnoses by means of endoscopic ultrasound, the importance, usefulness and safety of the procedure has been proven, which allows the detailed visualization of the lesions of the gastrointestinal tract, through this technique it is possible to visualize the extension to the mucosa of the tumors, is useful and accurate in the taking of sample for histological study of the tumoral lesions and other entities, which coincides with investigations carried out by authors such as Fugazza [8] and Kitano M [9] who raise that endoscopic ultrasound is an efficient diagnostic and therapeutic modality in the study of gastrointestinal diseases, is a minimally invasive technique with a low percentage of complications.

In his research Fugazza [8] states that there are few reports on the use of endoscopic ultrasound in children, which coincides with 
the systematization carried out by the authors, which is why the importance of this case study is derived, since in Cuba there is no there are reports associated with the use of endoscopic ultrasound in children.

Yi Jia in a study conducted in 2015 in Texas, reports his experience in the use of endoscopic ultrasound in 5 children, with a range of ages between 6 and 17 years, for the drainage of pancreatic pseudocyst, previously diagnosed by imaging studies, and evaluates the utility and impact of the technique, which concludes that endoscopic ultrasound is a safe and valuable technique for the pediatric population [5].

Similar results obtained Keane. $M$ and collaborators in a study conducted in 90 infants, of which 24 were studied by endoscopic ultrasound, where they did not experience adverse events related to the technique [9].

\section{Conclusions}

The importance of endoscopic ultrasound is verified, which allowed the histological diagnosis of the lesion to carry out the surgery. It is a simple technique with a minimum of complications. Added to this the fact that it is the first to be done to a scholar in Cuba according to the literature consulted, shows that despite the difficulties faced by health services in our country because of the blockade imposed for the United States, we continue to strive to provide quality care to society, from the science and humanism that characterizes us as one of the best health systems in the world.

\section{Bibliography}

1. Higuita AM., et al. "Tumor seudopapilar sólido del pancreas". Revista Colombiana de Cirugía 31.4 (2016): 289-295.

2. Paz Soldán Mesta C., et al. "Pancreatoduodenectomía por tumor sólido pseudopapilar de páncreas en niños”. Revista de Gastroenterología del Perú 37 (2017): 71-76.

3. Bender AM., et al. "Solid Pseudopapillary Neoplasm of the Pancreas in a Young Pediatric Patient: A Case Report and Systematic Review of the Literature". Pancreas 47 (2018): 13641368.

4. Jia Y., et al. "The therapeutic use of endoscopic ultrasonography in pediatric patients is safe: A case series". Saudi Journal of Gastroenterology 21 (2015): 391-395.
5. Laffita Estévez S., et al. "Algunas características clínico epidemiológicas de los tumores sólidos malignos en niños de Las Tunas". Rev Electron Zoilo 40 (2015).

6. Verdecia Cañizares C. "Cáncer pediátrico en Cuba”. Revista Cubana de Pediatría 89 (2017): 1-3.

7. Fugazza A., et al. "The role of endoscopic ultrasound in children with Pancreatobiliary and gastrointestinal disorders: a single center series and review of the literature". BMC Pediatrics 17 (2017): 203.

8. Kitano M and Yamashita Y. "New Imaging Techniques for Endoscopic Ultrasonography: Contrast-Enhanced Endoscopic Ultrasonography". Gastrointestinal Endoscopy Clinics of North America 27 (2017): 569-58.

9. Keane MG., et al. "Paediatric pancreaticobiliary endoscopy: a 21-year experience from a tertiary hepatobiliary centre and systematic literature review". BMC Pediatrics 18 (2018): 42.

\section{Volume 2 Issue 6 August 2019 \\ (C) All rights are reserved by Raúl Brizuela Quintanilla., et al.}

